\title{
Pediatric COVID-19: The Silent Spreaders are Not so Silent Anymore
}

\author{
Pooja Dewan ${ }^{1}$ Piyush Gupta ${ }^{1}$ \\ ${ }^{1}$ University College of Medical Sciences, Delhi, India
}

\begin{abstract}
Address for correspondence Piyush Gupta, MD, FAMS, FIAP, Professor of Pediatrics, University College of Medical Sciences, Delhi 110095, India (e-mail: prof.piyush.gupta@gmail.com).
\end{abstract}
Abstract
Keywords
- child
- coronavirus
- pandemic

The COVID-19 pandemic has been an enigma to all. Contrary to the initial perception that the novel coronavirus spares most kids, evidence has been emerging that children including neonates and infants are also infected. The clinical presentation in the pediatric age group has been reported as often atypical. Given the fact that children could be carriers of this deadly virus and hence act as spreaders, the need to recognize pediatric COVID-19 seems imminent.
The year 2019 ended on a threatening note as a cluster of cases of pneumonia attributed to a novel coronavirus strain (nCOV strain) was reported from Wuhan, Hubei province in China, to the World Health Organization (WHO). The mystery illness soon spread with a logarithmic rise in number of cases, and the first death was reported on January 11, 2020, from China. By the end of January 2020, the WHO had declared the mystery illness as a public health emergency of international concern (PHEIC) and by February 11, 2020, the illness was designated as “COVID-19." By March 10, 2020, the illness had spread to 114 countries, causing 118,950 cases of COVID-19 and 4296 deaths. WHO, although belatedly, declared COVID-19 as a global pandemic on March 11, 2020.

While the children were not a face of this pandemic, it was soon evident that COVID-19 was ruthless, for it spared no age-group, sex, race, or region. The pediatric cases were fewer, accounting for approximately 1 to $5 \%$ of diagnosed COVID-19 cases. Approximately, 90\% of cases in children were diagnosed as asymptomatic, mild, or moderate disease. The first pediatric case of severe acute respiratory syndrome (SARS)-CoV-2 infection was reported in Shenzen, China, on January 20, 2020.

In a large study from China, epidemiological characteristics of 2143 pediatric cases with suspected/confirmed COVID-19, between 16 January 2020 and 8 February 2020, were analyzed. ${ }^{1}$ Of these, 731 (34.1\%) were laboratory-confirmed COVID-19 cases with a median age of 7 years (interquartile range: $2-13$ years) and nearly $57 \%$ of these were boys. COVID-19 in children appeared to affect all pediatric ages with no gender difference, although infants appeared more vulnerable to severe disease. The proportion of severe and critical cases was $10.6 \%, 7.3 \%, 4.2 \%, 4.1 \%$ and $3 \%$ for the age-groups < 1 year, 1 to 5,6 to 10,11 to 15 , and 16 to 18 years. Overall, only $5.6 \%$ of children had severe infection with $13 \%$ of them developing multiorgan dysfunction syndrome (MODS)/SARS and $0.2 \%$ mortality.

A study from the United States analyzed the data from 2572 COVID-19 cases in children aged < 18 years with a median age of 11 years, which were reported till April 2, 2020. ${ }^{2}$ The pediatric cases accounted for $1.7 \%$ of the total cases and $57 \%$ of these were seen in boys. The proportion of cases was $15 \%, 11 \%, 15 \%, 27 \%$ and $32 \%$ for the agegroups < 1 year, 1 to 4,5 to 9,10 to 14 , and 15 to 17 years. Like the study from China, this study also attributed the source of infection to a COVID-19 patient in the household or community, or due to travel to an affected area, suggesting human-to-human transmission. The symptoms in COVID-19 affected children were milder. As much as $73 \%$ of affected pediatric cases reported fever, cough or shortness of breath against 93\% seen in adults aged 18 to 64 years. Again, 56\%, 54\%, and 13\% of COVID-19 cases in children reported fever, cough and shortness of breath, respectively, against $71 \%, 80 \%$ and $43 \%$ seen in their adult counterparts. As much as $5.7 \%$ of pediatric cases needed hospitalization against $10 \%$ in adults; $62 \%$ of infants, however, needed hospitalization. ${ }^{2}$ 
The manifestations of COVID-19 in children is emerging as a cause of worry, for this group may be mostly asymptomatic and hence responsible for spreading the disease among the adults, prompting the parents to caution theirs kids with a warning "No hugs or kisses for granny," a statement which may leave the kids baffled and emotionally disturbed. Other clinical presentations of COVID-19 in children include sore throat, running nose, loss of smell and taste, myalgias, bone pains, abdominal pain and diarrhea, all of which are also seen in adults. A pooled analysis revealed that an overall percentage of COVID-19 presenting as diarrhea was $10.4 \%{ }^{3}$ However, presentation of COVID-19 with gastrointestinal disturbances in children (more common in children compared with adults) can be perplexing for treating doctors, especially in tropical countries, where diarrhea due to bacterial pathogens is certainly more common; thereby, posing a diagnostic dilemma as to when and whom to test for COVID-19. The possibility of fecal oral transmission of COVID-19 has suggested the need for a rapid and effective modification of the current screening and diagnostic algorithms. Recently, "Covid Toes," a mimicker of frostbites, has been hailed as a new potential symptom observed in kids across a few European countries. ${ }^{4}$ Another unusual presentation can be with dermatitis or conjunctivitis. ${ }^{5}$ In Italy, pediatric COVID-19 had an uncanny resemblance to Kawasaki disease. ${ }^{6} \mathrm{~A}$ few infants with COVID-19 presenting with neurological symptoms like axial hypotonia, drowsiness and moaning have also been reported. ${ }^{7}$

The lesser prevalence of COVID-19 in children has been attributed to lesser opportunities for exposure due to home confinement with strict implementation of closure of educational institutions and recreational parks as a part of global containment strategies adopted across countries. Additionally, overprotection given by parents in the crisis times decreased the exposure in this cohort. It is also being debated that lesser prevalence of COVID-19 amongst Asians is due to the protective effect of routine BCG vaccination, as it has been shown to alter cell-mediated immunity in myriad ways. However, this presumption needs to be validated. Other theories which gained reason were differences in immune responses in children due to a developing immune system, leading to a lesser cytokine storm, lesser ACE-2 receptors in lungs, fewer comorbidities in children, and healthier respiratory tracts in children, all of which could possibly render COVID-19 in children as less severe.

Laboratory findings of COVID-19 in children also include an elevated procalcitonin (not so common in adults). Radiographic findings of COVID pneumonia in children also appear to be milder and less specific. CT changes observed in infected children include unilateral or bilateral multiple patchy, nodular, or speckled ground glass opacities, consolidation with surrounding halo sign, and/or infiltrating shadows in the middle and outer zone of the lung or under the pleura. ${ }^{89}$

Treatment of COVID-19 in children mainly depends on experience from adult counterparts due to limited data drawn from pediatric cases. There is no specific drug treatment for COVID-19; symptomatic and supportive treatment including oxygenation, and maintenance of fluid and electrolyte balance, so as to avoid aggravating the pulmonary edema, are the mainstay of therapy. A few studies have reported success with the use of IV glucocorticoids, antiviral drugs (like ribavirin, oseltamivir and interferon), IV immunoglobulin, and systemic antibiotics to treat the coexistent suspected bacterial infections. ${ }^{10,11}$ For newborns with severe acute respiratory distress syndrome (ARDS), surfactant therapy, inhaled nitric oxide, high-frequency oscillatory ventilation and extracorporeal membrane lung may be useful. COVID-19 neonates should be placed in negative pressure rooms or in rooms in which room exhaust is filtered through high-efficiency particulate air (HEPA) filters.

Currently, no evidence exists that COVID-19 can be transmitted transplacentally from infected mother to newborn, although the possibility of acquiring the infection from infected parturient mothers remains. ${ }^{12,13}$ Therefore, it may be suggested that mothers may breastfeed once their infection has been cured while wearing appropriate mask and maintaining respiratory and hand hygiene. In India, the youngest COVID-19 case was reported on April 1, 2020, from Kasturba Hospital, Mumbai, where a 6-day-old male neonate was detected with this contagion. ${ }^{14}$ The infection seemed to have been acquired postnatally as the room allocated to the mother for delivery in a hospital in Chembur had previously been housing another COVID- 19 positive patient; both the mother and baby were detected to be infected with the deadly virus.

Relatively fewer cases of infants confirmed to have COVID-19 have been reported; those who are infected have experienced mild illness. ${ }^{15}$ Rarely, deaths have also been reported among infants with COVID-19 infection. On March 29, 2020, the first infant who had tested positive for COVID-19 died in USA ${ }^{16}$ and subsequently deaths were reported amongst the pediatric age group from other countries as well. Belgium and UK reported their first casualties in a 12-year-old girl and 13-year-old boy, respectively, due to COVID-19. In India, the first COVID-19 child death was a 14 month-old-boy from Jamnagar, Gujarat, who succumbed to multiorgan dysfunction on April 8, 2020. ${ }^{17}$ Subsequently, three more infant deaths were reported from Kozhikode, ${ }^{18}$ Chandigarh $^{19}$ and New Delhi ${ }^{20}$ till April 26, 2020; three of these children had an underlying heart disease. - Table 1 depicts the of infant COVID-19 deaths in India.

Apart from the direct impact on the systemic health, several other ill effects of COVID-19 have come to the fore. The scenario where parents test positive, but kids are negative is bound to haunt the parents because who will care for the kids if the parents get quarantined. With no government mechanisms in place and kin reluctant to offer help, parents would have no option but to keep the kids with them and risk them with the contagion. Due to the social distancing measures that many countries have implemented, schools have been suspended nationwide in 188 countries, causing disruptions to daily routines of children and adolescents. ${ }^{21}$ Children with special education needs, such as those with autism spectrum disorder, are at risk for severe depression and self-harm. Alternate teaching strategies through online 
Table 1 Profile of infant COVID-19 deaths in India

\begin{tabular}{|c|c|c|c|}
\hline Age/sex & Place and date of death & Clinical presentation & Treatment \\
\hline 14 mo/male & $\begin{array}{l}\text { Jamnagar, Gujarat } \\
\text { April 8, } 2020\end{array}$ & $\begin{array}{l}\text { Multiorgan dysfunction Child also } \\
\text { had an underlying congenital heart } \\
\text { disease (ASD) Infection was acquired } \\
\text { from a relative who was positive for } \\
\text { COVID-19 }\end{array}$ & $\begin{array}{l}\text { Hydroxychloroquine } \\
\text { Azithromycin Steroids } \\
\text { Tocilizumab and Lopinavir } \\
\text { Supportive care }\end{array}$ \\
\hline $45 \mathrm{~d} / \mathrm{male}$ & $\begin{array}{l}\text { Kalawati Saran Children's Hospital, } \\
\text { New Delhi } \\
\text { April 18, } 2020\end{array}$ & Severe acute respiratory infection & Supportive care \\
\hline $4 \mathrm{mo} /$ female & $\begin{array}{l}\text { Kozhikode Medical College, Kerala } \\
\text { April 22, } 2020\end{array}$ & $\begin{array}{l}\text { Fever, cough, fast breathing and } \\
\text { seizure } \\
\text { Child also had an underlying } \\
\text { congenital heart disease (ASD) }\end{array}$ & Ventilation and supportive care \\
\hline $6 \mathrm{mo} /$ female & $\begin{array}{l}\text { Post-graduate Institute of Medical } \\
\text { Education and Research (PGIMER), } \\
\text { Chandigarh } \\
\text { April 23, } 2020\end{array}$ & $\begin{array}{l}\text { History of underlying heart disease } \\
\text { History of } 36 \text {-day stay in a hospital } \\
\text { in Ludhiana, following which she was } \\
\text { shifted to PGIMER, Chandigarh }\end{array}$ & Ventilation and supportive care \\
\hline
\end{tabular}

Abbreviation: ASD, atrial septal defect.

platforms have led to an unprecedented increase in screen time for children, exposing them to possible consequences like obesity and cyber bullying.

The ongoing COVID-19 pandemic is bound to have lasting effects on people and their nutrition, especially for children and elderly. School closures in several developing countries also mean a lack of access to the resources like mid-day meals, increasing the risk of malnutrition. In the face of the pandemic, routine healthcare and services have been impacted. Children with chronic disorders like blood disorders, cancers, HIV, diabetes and renal/hepatic diseases have been left in the lurch, having to fend for themselves. The routine immunization activities have taken a hit. The UNICEF has anticipated that more than 117 million children across 37 countries could also miss out on measles vaccine because of the pandemic, endangering the gains acquired by sustained immunization campaigns. ${ }^{22}$

It is pertinent to note that the data from children with COVID-19 definitely underestimates the prevalence of the disease severity because at the time of publication, details like hospitalization status, presence of comorbidities and outcomes were missing for several cases. Moreover, as the prevalence of asymptomatic carriers is much higher in this group, there is underestimation of the true prevalence of COVID-19 in children who could be the "silent spreaders" of this disease. The real picture of COVID-19 may emerge over the coming months with systematic surveillance as well as improved diagnostic and treatment algorithms.

\section{Authors' Contributions}

P.G. conceptualized the study. P.D. searched the literature and prepared an initial draft. P.G. provided critical inputs. Both authors approved the final version of the manuscript.

\section{Conflict of Interest}

None declared.

\section{References}

1 Dong Y, Mo X, Hu Y, et al. Epidemiology of COVID-19 among children in China. Pediatrics 2020. Doi: 10.1542/ peds.2020-0702

2 CDC COVID-19 Response Team. Coronavirus disease 2019 in children - United States, February 12-April 2, 2020. Morb Mortal Wkly Rep 2020;69(14):422-426

3 D'Amico F, Baumgart DC, Danese S, Peyrin-Biroulet L. Diarrhea during COVID-19 infection: pathogenesis, epidemiology, prevention and management. Clin Gastroenterol Hepatol 2020. Doi: 10.1016/j.cgh.2020.04.001

4 USA Today. What are 'COVID toes'? Doctors Discover Symptom of Coronavirus Mostly Seen in Kids. Available at: https:// www.usatoday.com/story/news/health/2020/04/21/coronavirus-covid-toes-may- symptom-covid-19-young-people/2994930001/. Accessed April 27, 2020

5 Wu P, Liang L, Chen C, Nie S. A child confirmed COVID-19 with only symptoms of conjunctivitis and eyelid dermatitis. Graefes Arch Clin Exp Ophthalmol 2020. Doi: 10.1007/ s00417-020-04708-6

6 Viner RM, Whittaker E. Kawasaki-like disease: emerging complication during the COVID-19 pandemic. Lancet 2020. Doi: 10.1016/S0140-6736(20)31129-6

7 Nathan N, Prevost B, Corvol H. Atypical presentation of COVID-19 in young infants. Lancet 2020. Doi:10.1016/ S0140-6736(20)30980-6

8 Zimmermann P, Curtis N. Coronavirus infections in children including COVID-19: an overview of the epidemiology, clinical features, diagnosis, treatment and prevention options in children. Pediatr Infect Dis J 2020;39(5):355-368

9 Xia W, Shao J, Guo Y, Peng X, Li Z, Hu D. Clinical and CT features in pediatric patients with COVID-19 infection: Different points from adults. Pediatr Pulmonol 2020;55(5):1169-1174

10 Sun D, Li H, Lu XX, et al. Clinical features of severe pediatric patients with coronavirus disease 2019 in Wuhan: a single center's observational study. World J Pediatr 2020. Doi: 10.1007/s12519-020-00354-4

11 Chen ZM, Fu JF, Shu Q, et al. Diagnosis and treatment recommendations for pediatric respiratory infection caused by the 2019 novel coronavirus. World J Pediatr 2020. Doi: 10.1007/ s12519-020-00345-5 
12 Chen $\mathrm{Y}$, Peng $\mathrm{H}$, Wang $\mathrm{L}$, et al. Infants born to mothers with a new Coronavirus (COVID-19) Front Pediatr 2020. Doi: 10.3389 /fped.2020.00104

13 Chen H, Guo J, Wang C, et al. Clinical characteristics and intrauterine vertical transmission potential of COVID-19 infection in nine pregnant women: a retrospective review of medical records. Lancet 2020;395(10226):809-815

14 Deccan Herald. India's Youngest Coronavirus Case in Mumbai. Available at: www.deccanherald.com. Accessed June 3, 2020

15 Wei M, Yuan J, Liu Y, Fu T, Yu X, Zhang ZJ. Novel coronavirus infection in hospitalized infants under 1 year of age in China. JAMA 2020. Doi: 10.1001/jama.2020.2131

16 Infant infected with COVID-19 dies in US. Available at: https:// www.theweek.in/news/world/2020/03/29/infant-infectedwith-covid-19-dies-in-us.html. Accessed June 8, 2020

17 India Today. Coronavirus in India: 14-month-old dies of Covid-19 in Gujarat's Jamnagar. Available at: https://www. indiatoday.in/india/story/coronavirus-india-14-monthold-dies-covid-19-gujarat-jamnagar-1664486-2020-04-08. Accessed June 8, 2020
18 Times of India. Four-Month-Old Baby from Malappuram Dies of Covid-19. Available at: https://timesofindia.indiatimes.com/ city/kozhikode/four-month-old-baby-from-malappuram-diesof-covid-19/articleshow/75342997.cms. Accessed June 8, 2020

19 NDTV. 6-Month-Old Girl Infected with Coronavirus Dies at Chandigarh Hospital. Available at: https://www.ndtv.com/ chandigarh-news/covid-19-6-month-old-girl-infected-withcoronavirus-dies-at-chandigarh-hospital-2217000. Accessed June 3, 2020

20 NDTV. One-and-a-Half Month Old Baby Dies of Covid-19 at Delhi Hospital. Available at: ndtv.com/delhi-news/coronavirus-india-one-and-a-half-month-old-baby-dies-of-covid-19at-delhi-hospital-2214621. Accessed June 3, 2020

21 Lee J. Mental health effects of school closures during COVID-19. Lancet Child Adolesc Health 2020. Doi: 10.1016/ S2352-4642(20)30109-7

22 World Health Organization. More than 117 Million Children at Risk of Missing Out on Measles Vaccines, as COVID-19 Surges. Available at: https://www.who.int/immunization/ diseases/measles/statement_missing_measles_vaccines_ covid-19/en/. Accessed April 27, 2020 